\title{
Germ cell-specific localization of immunoreactive riboflavin carrier protein in the male golden hamster: appearance during spermatogenesis and role in sperm function
}

\author{
A Sreekumar ${ }^{1}$, K K Acharya ${ }^{1}$, H S Lalitha ${ }^{1}, \mathrm{~S} \mathrm{~S} \mathrm{Indi}{ }^{2}, \mathrm{P} \mathrm{Bali}^{1}$ and P B Seshagiri ${ }^{1}$ \\ ${ }^{1}$ Department of Molecular Reproduction, Development and Genetics and ${ }^{2}$ Department of Microbiology and \\ Cell Biology, Indian Institute of Science, Bangalore 560 012, India
}

Correspondence should be addressed to P B Seshagiri; Email: polani@mrdg.iisc.ernet.in

(A Sreekumar and K K Acharya contributed equally to this work)

\begin{abstract}
Riboflavin carrier protein ( $\mathrm{RCP})$ is a phosphoglycoprotein $(37 \mathrm{kDa})$ that is well studied in chicken. An immunologically crossreacting protein was identified in mammals and active immunization of male rats and bonnet monkeys with chicken RCP lead to an $\sim \mathbf{8 0} \%$ reduction in fertility. However, the physiological mechanism responsible for inhibition of male fertility has not been investigated. Moreover, information on the cell type-specific localization and the origin of immunoreactive RCP during spermatogenesis is extremely limited. Hence, studies were carried out to determine the pattern of expression of immunoreactive RCP during spermatogenesis and its role in sperm function in the golden hamster. Immunoreactive RCP was germ cell-specific, found to be associated with the acrosome-organizing region of early spermatids and showed interesting patterns of immunolocalization during late stages of spermiogenesis. Mature spermatozoa exhibited acrosome-specific localization, mainly in the peri-acrosomal membrane. The immunoreactive protein was undetectable in (non)gonadal somatic cells tested. The protein had a molecular mass of 45-55 kDa and was biosynthesized by round spermatids. The acrosome-specific localization of immunoreactive RCP was unchanged during capacitation, but it was substantially lost during acrosome reaction. Functional studies indicated that treatment of spermatozoa with anti-RCP antibodies did not have any effect on either capacitation or acrosome reaction, but markedly reduced the rate of sperm penetration into zona-free hamster oocytes. These results show the existence of male germ cell-specific immunoreactive RCP, having a potential role in sperm-egg interaction in hamsters. Also the pattern of immunoreactive-RCP localization makes it an ideal marker to monitor development of acrosome in mammalian spermatozoa.

Reproduction (2005) 129 577-587
\end{abstract}

\section{Introduction}

During mammalian spermatogenesis, the male germ cells undergo a complex and prolonged differentiation process to develop into spermatozoa. The post-meiotic phase of spermatogenesis, also known as spermiogenesis, is characterized by remarkable morphological and biochemical changes in germ cells with the formation of functionally important organelles, namely the acrosome and flagellum. A completely formed testicular sperm attains functional maturation upon capacitation and acrosome reaction, and thus acquires the ability to fertilize the oocyte (Yanagimachi 1994). The acrosome reaction, the hallmark of sperm functional maturation, involves the release of a number of proteases, which enable the sperm to penetrate the oocyte (Yanagimachi 1994). The acrosome, thus, is a storehouse for a large number of proteins known to play a role in the functional maturation of spermatozoa. A variety of such proteins have been reported to be present/expressed specifically in the germ cells, particularly during sperm formation. Discovering the origin, distribution and functional role of such proteins is essential for a complete understanding of spermatogenesis. Several of these proteins could be potential markers of male fertility/infertility and/or cancer (Dean \& Moul 1998, Jager et al. 2001). Furthermore, many of the germ cell proteins are immunogenic and serve as potential target molecules for immunocontraception in humans (Diekman \& Herr 1997, Naz 2000). Hence, it is important to study in detail proteins associated with the male germ cells.

Among the proteins associated with the male reproductive system is a group belonging to the family of vitamin carriers. These include retinol-binding protein (Davis \& Ong 1992) and riboflavin carrier protein (RCP; Adiga et al. 1997). These are believed to be involved in the transportation of micronutrients across the blood testis barrier 
(Adiga et al. 1997). Immunoreactive RCP has been localized in the sperm head region in some mammals (Bhat et al. 1995) and is implicated to play an important role in mammalian reproduction. Earlier studies have indicated a marked reduction in male fertility $(\sim 80 \%)$, both in rodents and primates, following active immunization against chicken RCP (Adiga et al. 1997). However, the mechanism by which anti-RCP antibodies bring about this inhibition of fertility has not been well understood. Besides, the biochemical nature of the immunoreactive RCP, its origin and cellular localization during spermatogenesis as well as its role during sperm-egg interaction have not been defined clearly. In view of these shortcomings, we examined the occurrence and characterization of immunoreactive RCP in male reproductive tissues and attempted to characterize it and determine its functional role in the golden hamster. We chose the golden hamster for these studies since it is an ideal and important animal model for studies involving mammalian sperm structure and function.

\section{Materials and Methods}

\section{Animals}

Adult golden hamsters (Mesocricetus auratus) of 3 months old were used for the study. Animals were housed under a 14-h:10-h light/dark cycle with normal temperature and humidity. For some experiments, 21-day-old males were used. Animals were killed by cervical dislocation, and desired tissues were collected for various purposes as described below. All animal experiments were conducted according to the guidelines set by the Indian National Science Academy, New Delhi, India.

\section{Preparation of enriched population of round spermatids}

Enriched populations of round spermatids were obtained from hamster testis $(n=4)$ by centrifugal elutriation (Bucci et al. 1986). Briefly, testes were collected in Dulbecco's minimum essential medium (MEM), decapsulated, minced and digested with collagenase $(0.04 \%$ in Dulbecco's MEM with $25 \mathrm{mM}$ Hepes and $10 \mu \mathrm{g} / \mathrm{ml}$ DNase) for $30 \mathrm{~min}$, at $32^{\circ} \mathrm{C}$ in a water bath with gentle shaking. The cells were centrifuged at $1000 \mathrm{~g}$, washed and resuspended in $\mathrm{Ca}^{2+}$ - and $\mathrm{Mg}^{2+}$-free PBS containing $0.1 \%$ glucose and $0.2 \%$ BSA. These were then loaded into a JE6 elutriator rotor (Beckmann Coulter, Fullerton, CA, USA). Fractions $(150 \mathrm{ml})$ containing enriched populations of specific cell types were obtained by varying the rotor speed and flow rates. The enriched cells in each fraction were recovered by centrifugation at $100 \mathrm{~g}$ for $7 \mathrm{~min}$, washed once and resuspended in PBS. An aliquot of each cell population was fixed in $70 \%$ ethanol for DNA flow-cytometric analysis (FACS; Becton and Dickinson, Franklin Lakes, NJ, USA) and the percentages of individual germ cell types in different fractions were assessed (Aravindan et al. 1990). About $70 \%$ enrichment of round spermatids was achieved and the preparation was used for the study.

\section{${ }^{35}$ S]Methionine labeling of isolated round spermatids and immunoprecipitation}

Enriched preparation of round spermatids, obtained by centrifugal elutriation, were incubated, in Dulbecco's MEM lacking L-methionine and L-cysteine, supplemented with $100 \mathrm{U} / \mathrm{ml}$ penicillin (Invitrogen, Carlsbad, CA, USA) and $100 \mu \mathrm{g} / \mathrm{ml}$ streptomycin for $8 \mathrm{~h}$ at $32{ }^{\circ} \mathrm{C}$, in an atmosphere of $5 \% \quad \mathrm{CO}_{2}$ in humidified air. $\left[{ }^{35} \mathrm{~S}\right]$ Methionine (specific activity, $1000 \mathrm{Ci} / \mathrm{mmol}$; New England Nuclear, Boston, MA, USA) was added at a concentration of $50 \mu \mathrm{Ci} / \mathrm{ml}$ (O'Brien 1987). Cells were cultured in $60 \mathrm{~mm}$ plastic tissue-culture dishes (Falcon Plastics, Oxnard, CA, USA) containing $6 \mathrm{ml}$ medium, at a density of $5 \times$ $10^{6} \mathrm{cell} \mathrm{s} / \mathrm{ml}$. At the end of the culture period, the cells were harvested and frozen at $-70^{\circ} \mathrm{C}$.

The cells were later solubilized in an equal volume of RIPA buffer $(0.5 \mathrm{M}$ Tris/ $\mathrm{HCl}$ buffer, $\mathrm{pH} 7.5$, containing $150 \mathrm{mM} \mathrm{NaCl}, 0.1 \%$ SDS, $1 \%$ Triton X100 and 1\% deoxycholate) with protease inhibitors (Complete Mini; Boehringer Mannheim, Mannheim, Germany) and $255 \mu \mathrm{mol}$ each of L-methionine and L- cysteine (Sigma, St Louis, MO, USA). This was then subjected to four or five cycles of homogenization (30 s/cycle). The homogenate was clarified by centrifugation at $7000 \mathrm{~g}$ for $30 \mathrm{~min}$ at $4{ }^{\circ} \mathrm{C}$. The supernatant was preadsorbed on a column containing rabbit non-immune IgG coupled to CNBr-Sepharose 6B (Sigma) for $4-12 \mathrm{~h}$ at $4{ }^{\circ} \mathrm{C}$. The unbound fraction was divided into two halves and treated with either $100 \mu \mathrm{g} / \mathrm{ml}$ anti-RCP IgG (raised using published protocols against purified chicken RCP; White \& Merrill 1988) or nonimmune IgG and incubated for $12 \mathrm{~h}$ at $4{ }^{\circ} \mathrm{C}$. The antigenantibody complex was adsorbed on to $100 \mu \mathrm{l} / \mathrm{ml}$ Protein $\mathrm{G}$-Sepharose (Sigma) for $4-6 \mathrm{~h}$ at $4{ }^{\circ} \mathrm{C}$. The adsorbed beads were washed with chilled RIPA buffer followed by PBS, and subjected to electrophoresis by SDS/PAGE $(10 \%$ gel; Laemmli 1970). The gel was processed for flourography using Enhancer (New England Nuclear), dried and exposed to X-Omat K X-ray films (Eastman Kodak Company, Rochester, NY, USA).

\section{Preparation of cauda epididymal (CE) spermatozoa}

Epididymal spermatozoa were collected in Dulbecco's PBS (DPBS) by puncturing the distal tubules of the cauda epididymism, in the region devoid of capillaries, using a 26 guage needle, as per standardized protocol (Bavister \& Andrews 1988, Ain et al. 1999). For immunoblot analysis, the caudal content was filtered through a nylon mesh and the filtrate was spun at $1000 \mathrm{~g}$ for $10 \mathrm{~min}$ at $4{ }^{\circ} \mathrm{C}$. The sperm pellet was washed thrice with PBS while the supernatant was further clarified at $12000 \mathrm{~g}$ for $30 \mathrm{~min}$ at $4{ }^{\circ} \mathrm{C}$ and both were subjected to immunoblot analysis. 


\section{Immunoblot analysis}

Total proteins $(\sim 100 \mu \mathrm{g})$ from either CE contents or CE sperm or CE contents devoid of sperm were separated by electrophoresis on $\mathrm{SDS} / 10 \%$ polyacrylamide gels and were blotted on to nitrocellulose membrane (Towbin et al. 1979). After blocking the non-specific sites, the blots were treated with $1 \mu \mathrm{g} / \mathrm{ml}$ of either anti-RCP IgG or nonimmune $\lg G$ or pre-adsorbed anti-RCP IgG (using a 100fold excess of chicken RCP). After washing with PBS-T (PBS with $0.1 \%$ Tween-20), the blots were treated with 1:3000 dilution of anti-rabbit horseradish-peroxidase-conjugated antibodies raised in goat (Sigma). The immunoreactive bands were visualized using the enhanced chemiluminiscence detection system (ECL Plus; Amersham Biosciences, Piscataway, NJ, USA).

\section{Immunocytochemistry}

Testis, epididymis and somatic tissues tested were all fixed in Bouin's fluid for $24 \mathrm{~h}$. Tissues were washed, dehydrated, embedded in paraffin wax and $5 \mu \mathrm{m}$-thick sections were cut using a rotary microtome (1090A; Weswox Optik, MT, USA). Sections were placed on poly-L-lysine $(0.01 \%$ in DPBS)-coated slides, deparaffinized in xylene and rehydrated in a graded series of ethanol. Similarly, round spermatids, obtained after centrifugal elutriation, and epididymal spermatozoa were resuspended in DPBS containing $1 \%$ BSA and spotted on to poly-L-lysine-coated slides. The slides containing tissue sections or cells were treated with methanol/hydrogen peroxide (49:1) to block endogenous peroxidase activity. Nonspecific sites were blocked using DPBS containing 1\% BSA and 5\% normal goat serum overnight at $4{ }^{\circ} \mathrm{C}$. After a brief rinse with PBS, slides were incubated with $100 \mu \mathrm{g} / \mathrm{ml}$ each of either antiRCP IgG or non-immune IgG. Antibodies against peptide stretches 33-49 (CYA) or 64-83 (CED) of chicken RCP was also used at a dilution of 1:50 for some experiments. Similarly, antibodies to peptide stretch 130-147 (CGE) of avian RCP were used at 1:100 dilution (Monaco 1997, Subramanian et al. 2000), while those against SDS-denatured reduced carboxy-methylated RCP (SDS-RCM-RCP) were used at 1:1000 dilution (these antibodies were a kind gift from Professor PR Adiga). The slides were washed thrice with PBS-T and were further incubated with goat anti-rabbit horseradish peroxidase conjugate $(1: 1000)$ for $4 \mathrm{~h}$ at room temperature. After washing, immunoreactivity was detected using $0.05 \%$ diaminobenzidene and $0.015 \%$ hydrogen peroxide. The slides were counter stained with hematoxylin, dehydrated and mounted with DPX.

\section{Immunogold electron microscopy}

The CE spermatozoa were collected in PBS and fixed in $0.5 \%$ glutaraldehyde and 3\% paraformaldehyde in PBS for $30 \mathrm{~min}$. After blocking the aldehyde groups using $0.1 \mathrm{M}$ glycine, they were dehydrated in graded ethanol series and cleared in propylene oxide. The sperm were embedded in spur resin and gold interference sections were cut and placed on nickel grids. They were then incubated in DPBS containing 1\% BSA and 5\% normal goat serum overnight at $4{ }^{\circ} \mathrm{C}$. Anti-RCP IgG or non-immune IgG was used at $100 \mu \mathrm{g} / \mathrm{ml}$ in blocking solution and allowed to react with the sections at $4{ }^{\circ} \mathrm{C}$ for $48 \mathrm{~h}$. After extensive washing of the grids in drops of DPBS, sections were incubated for $12 \mathrm{~h}$ in a 1:50 dilution of goat anti-rabbit gold conjugate ( $5 \mathrm{~nm}$ gold particles; Sigma). Sections were washed in DPBS and fixed in 5\% glutaraldehyde for $30 \mathrm{~min}$. They were then stained with $1 \%$ uranyl acetate and lead citrate and observed at $80 \mathrm{KV}$ accelerating voltage under a Joel 100CX electron microscope.

\section{In vitro capacitation and induction of acrosome reaction of hamster sperm}

Spermatozoa from the distal tubules of the CE were recovered into Tyrode's medium containing lactate, pyruvate and polyvinyl alcohol (TLP-PVA) supplemented with $3 \%$ BSA and cultured at $37^{\circ} \mathrm{C}$ in an atmosphere of $5 \% \mathrm{CO}_{2}$ in air. About $1 \times 10^{4}$ spermatozoa were added to either medium alone or medium containing $10 \mu \mathrm{g} / \mathrm{ml}$ of either nonimmune $\lg \mathrm{G}$ or anti-RCP $\lg \mathrm{G}$ and cultured for $6 \mathrm{~h}$. At every $2 \mathrm{~h}$ interval, percentage of sperm motility and quality of motility (score, $0-5$ ) were assessed and sperm motility index (SMI) was calculated (Bavister \& Andrews 1988, Ain et al. 1999). Acrosome reaction of viable spermatozoa (minimum of 700 sperm/treatment) was assessed after $4 \mathrm{~h}$ of culture by detecting the presence or absence of acrosomal cap under light microscope at $400 \times$ (Bavister et al. 1978). An aliquot of the spermatozoa undergoing capacitation or acrosome reaction was also washed and processed for immunocytochemistry.

\section{Hamster egg-penetration assay (HEPA)}

Adult female hamsters were superstimulated by i.p. injection of $30 \mathrm{IU}$ pregnant mare's serum gonadotropin, on the day of post-estrous discharge, followed $56 \mathrm{~h}$ later by $30 \mathrm{IU}$ human chorionic gonadotropin (hCG). Oocytes retrieved by puncturing the swollen ampullary region of excised oviducts at $16 \mathrm{~h}$ post-hCG, and were treated with $1 \mathrm{mg} / \mathrm{ml}$ hyaluronidase and $0.01 \mathrm{mg} / \mathrm{ml}$ soybean trypsin inhibitor to remove cumulus cells (Bavister 1989). The cumulus-free oocytes were denuded using acid Tyrode's solution for 1-2 min. These were washed and incubated with $1 \times 10^{4}$ spermatozoa exposed to either anti-RCP $\operatorname{lgG}$ or non-immune $\lg \mathrm{G}$ or remained untreated for $2 \mathrm{~h}$. After co-incubation, oocytes were washed, fixed with $3 \%$ glutaraldehyde and stained with lacmoid solution $(0.25 \%$ in $45 \%$ acetic acid). They were then observed under an Olympus IMT2 inverted microscope.

\section{Statistical analysis}

The results of Fig. 8, Table 1 and acrosome-reaction data were from a minimum of three experiments. Values 
Table 1 Assessment of fertilizing potential of anti-RCP-IgG-treated spermatozoa in the golden hamster Values shown are means \pm S.E.M.

\begin{tabular}{|c|c|c|c|c|c|}
\hline \multicolumn{2}{|c|}{ Treatment } & \multirow{2}{*}{$\begin{array}{l}\text { Number of oocytes } \\
\text { co-cultured }\end{array}$} & \multirow{2}{*}{$\begin{array}{c}\text { Percentage of oocytes } \\
\text { penetrated }\end{array}$} & \multirow{2}{*}{$\begin{array}{c}\text { Number of sperm per } \\
\text { oocyte (range) }\end{array}$} & \multirow{2}{*}{$\begin{array}{r}\text { Number of sperm pe } \\
\text { penetrated oocyte }\end{array}$} \\
\hline Oocyte & Sperm & & & & \\
\hline Untreated & Untreated & 53 & $88.3 \pm 4$ & $7.2 \pm 0.8^{\mathrm{a}, \mathrm{b}}(3-17)$ & $8.1 \pm 0.6^{a, b}$ \\
\hline Untreated & Non-immune IgG & 53 & $88.6 \pm 4.3$ & $7.3 \pm 1.2^{\mathrm{a}}(4-20)$ & $8.3 \pm 1.0^{\mathrm{a}}$ \\
\hline Untreated & Anti-RCP IgG & 76 & $74.7 \pm 5.2$ & $1.9 \pm 4^{b}(1-7)$ & $2.5 \pm 0.3^{b}$ \\
\hline
\end{tabular}

${ }^{a}$ Values do not differ significantly $(\mathrm{P}>0.1)$

${ }^{b}$ Values differ significantly $(P<0.001)$

shown were means \pm S.E.M. and were analyzed by Student's $t$ test. Compared values were considered significantly different if $P<0.05$.

\section{Results}

\section{Localization of immunoreactive RCP in testis, epididymis and spermatozoa}

Testicular sections treated with anti-RCP antibodies showed intense staining in the germ cells located in the interior, towards the lumen of the seminiferous tubules (Fig. 1A and C). Immunostaining was undetectable in Sertoli cells, Leydig cells (Fig. 1A), sections of immature testis and accessory reproductive or non-reproductive organs (data not shown). No staining was seen in the testicular sections treated with either non-immune IgG (Fig. 1B) or antigen pre-adsorbed anti-RCP antibodies (Fig. 1D). Examination of immunostaining in germ cells revealed that the staining was specifically confined to spermatids (Fig. 2), with no staining associated with either spermatogonia or pachytene spermatocytes (Fig. 2B and C). The staining first appeared in pro-acrosomal granules/vesicles in the form of an arc in the peri-nuclear region of early spermatids (Fig. 2A and B). While the intensity of staining in the perinuclear region gradually increased during the later stages of spermatogenesis, diffused and mild staining was observed in the cytoplasm in the later stages of elongating spermatids (Fig. 2C).

Observations on immunostaining obtained with isolated spermatid population revealed the antigen to be localized during steps $1-17$ of spermiogenesis (Fig. 3), as described elsewhere (Clermont 1954). Faint staining was first observed in pro-acrosomal granules/vesicles at the peri-nuclear region of the Golgi-phase spermatids (Fig. 3, steps $1-4)$. These migrate to the anterior part of the spermatid, i.e. the acrosome-organizing region (characterized by the presence of an eccentrically located nucleus). In the later stages of spermatid development, the staining was detected in the cytoplasm (Fig. 3, step 5). During steps 6-16 of spermiogenesis, intense and uniform staining was observed in both the cytoplasm and the developing acrosome. Interestingly, in the testicular sperm (steps 16 and 17) excess immunostaining, associated with the Golgi remnants/granules, was excluded from the tail region in the form of a residual body (Fig. 3, step 16). The immunoreactive protein finally localized specifically to the acrosomal region of mature epididymal spermatozoa (Fig. 3, CE-sperm). A similar pattern of immunostaining was obtained in the mature epididymal sperm using antibodies to SDS-RCM-RCP or various peptide fragments (data not shown).

Following the establishment of organelle-specific localization of immunoreactive RCP during testicular development of spermatozoa, it was of interest to assess the pattern of immunostaining for RCP during epididymal and functional maturation of the sperm. In epididymal tissue sections, intense staining was observed on the luminal spermatozoa and was undetectable in the epithelial cells or the inter-tubular space (Fig. 4). Further characterization of this immunoreactive protein using immunoblot analysis confirmed its association with the total CE content and CE sperm (data not shown). Encouraged by cell-type and organelle-specific localization of the sperm-associated RCP, it was interesting to investigate the ultrastructural association of the protein in spermatozoa using immunogold electron microscopy. This indicated the distribution of immunoreactive RCP on the sperm head, specifically with the matrix and the peri-acrosomal membranes (Fig. 5A, outer acrosomal and plasma membranes). Also, a few gold particles were seen in the inner acrosomal membrane (Fig. 5A). No staining was observed in nonimmune-lgG-treated sections (Fig. 5B).

\section{Biochemical characterization of immunoreactive $\mathbf{R C P}$ in spermatids and spermatozoa}

Immunoblot analysis of total proteins from spermatids showed the presence of three bands, of 29, 45 and $55 \mathrm{kDa}$ (Fig. 6A). Moreover, $\left[{ }^{35} \mathrm{~S}\right]$ methionine radiolabeling of the enriched population of round spermatids in culture followed by immunoprecipitation using anti-RCP antibodies showed the ability of these germ cells to synthesize the immunoreactive protein during their development (Fig. 6B). Importantly, analysis of the immunoprecipitate showed a major protein of $45 \mathrm{kDa}$ (Fig. 6B). Further analysis of sperm-associated RCP using urea-extracted lysates revealed an intense band in the $45 \mathrm{kDa}$ region (Fig. 6C).

\section{Role of immunoreactive RCP in sperm function}

Following identification of the germ cell-specific immunoreactive RCP, it was interesting to investigate the possible role of this protein during sperm function. As an initial 

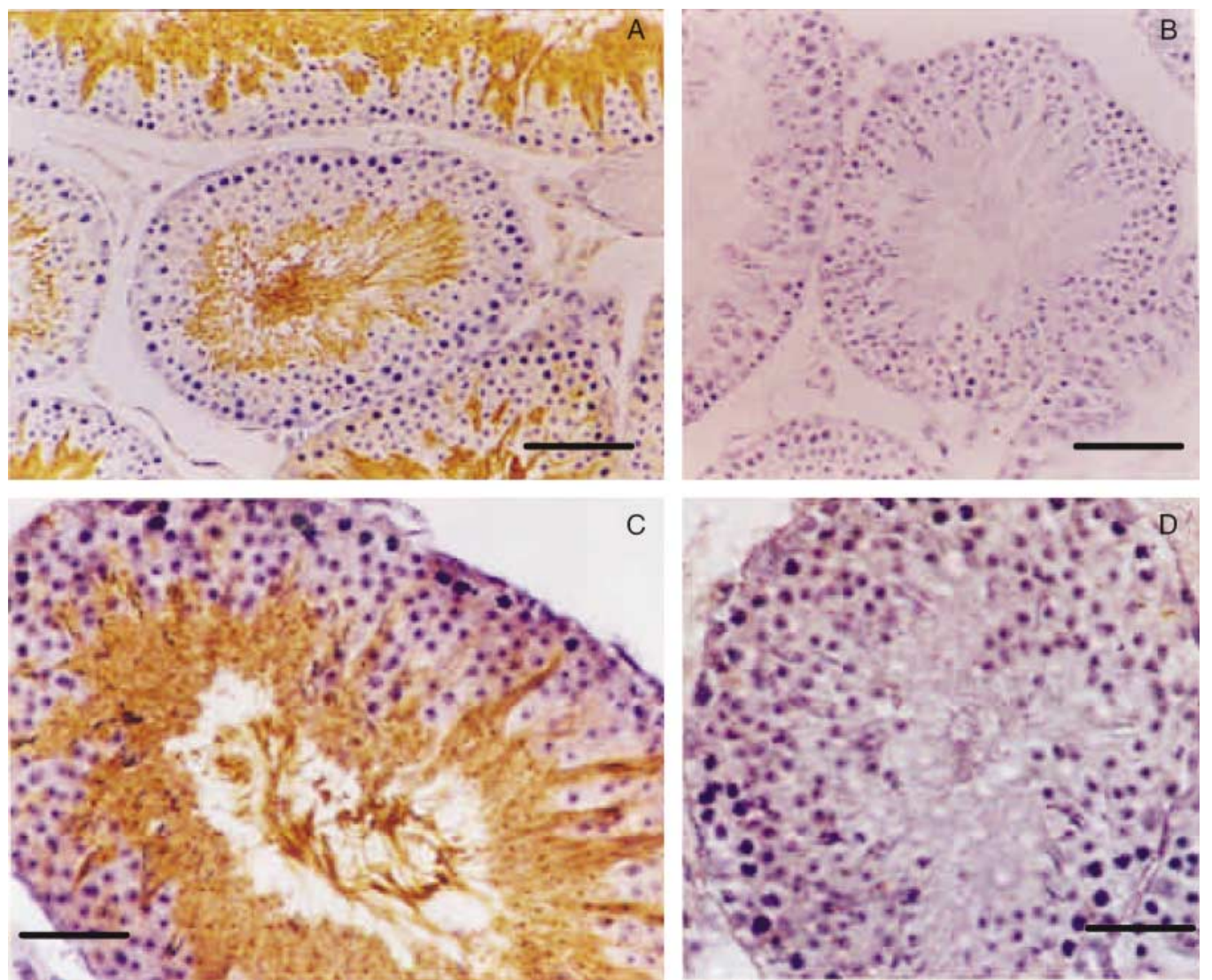

Figure 1 Localization of immunoreactive RCP in testicular sections from hamster. Immunoreactive RCP was localized in elongating spermatids and later cell stages of spermiogenesis but not in pre-meiotic germ cells, Sertoli cells or Leydig cells (A, C). No staining was observed in nonimmune-lgG-treated (B) or preadsorbed antibody-treated sections (D). Original magnifications: A and B, $\times 200 ; C$ and D, $\times 500$. Scale bars: $A$ and $B, 69 \mu \mathrm{m} ; C$ and $\mathrm{D}, 42 \mu \mathrm{m}$.
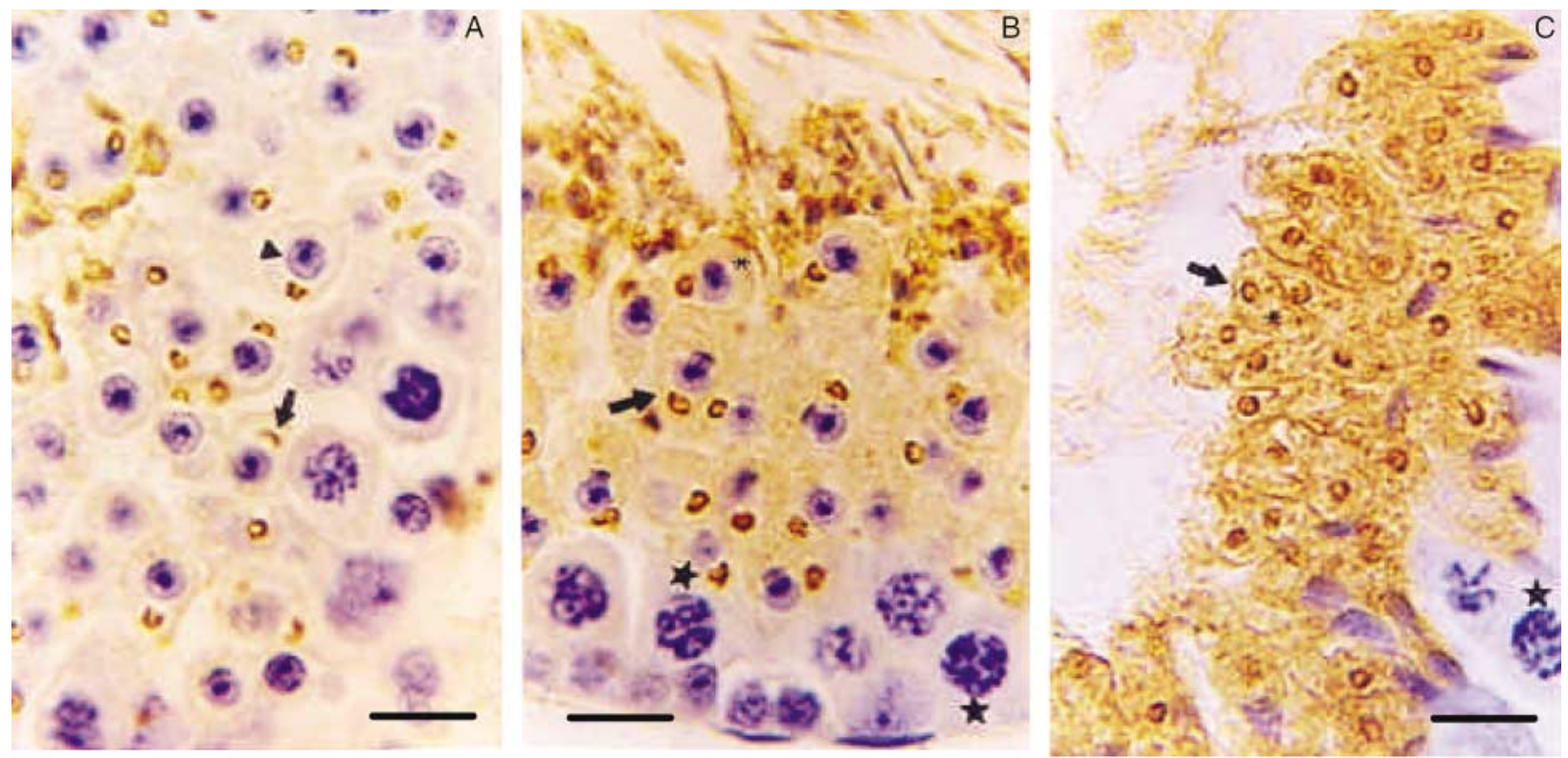

Figure 2 Localization of immunoreactive RCP in round and elongating spermatids. Immunoreactive RCP first appeared in the acrosome-organizing region in the early round spermatid (A; arrow). In the later stages of the round spermatid, the staining also appeared in the cytoplasm (B). In elongating spermatids, intense staining was observed both in the acrosome-organizing region and the cytoplasm (C; arrow and asterisk). No staining was observed in pachytene spermatocytes (B and C; star). Original magnification, $\times 500$. Scale bars: $17 \mu \mathrm{m}$. 

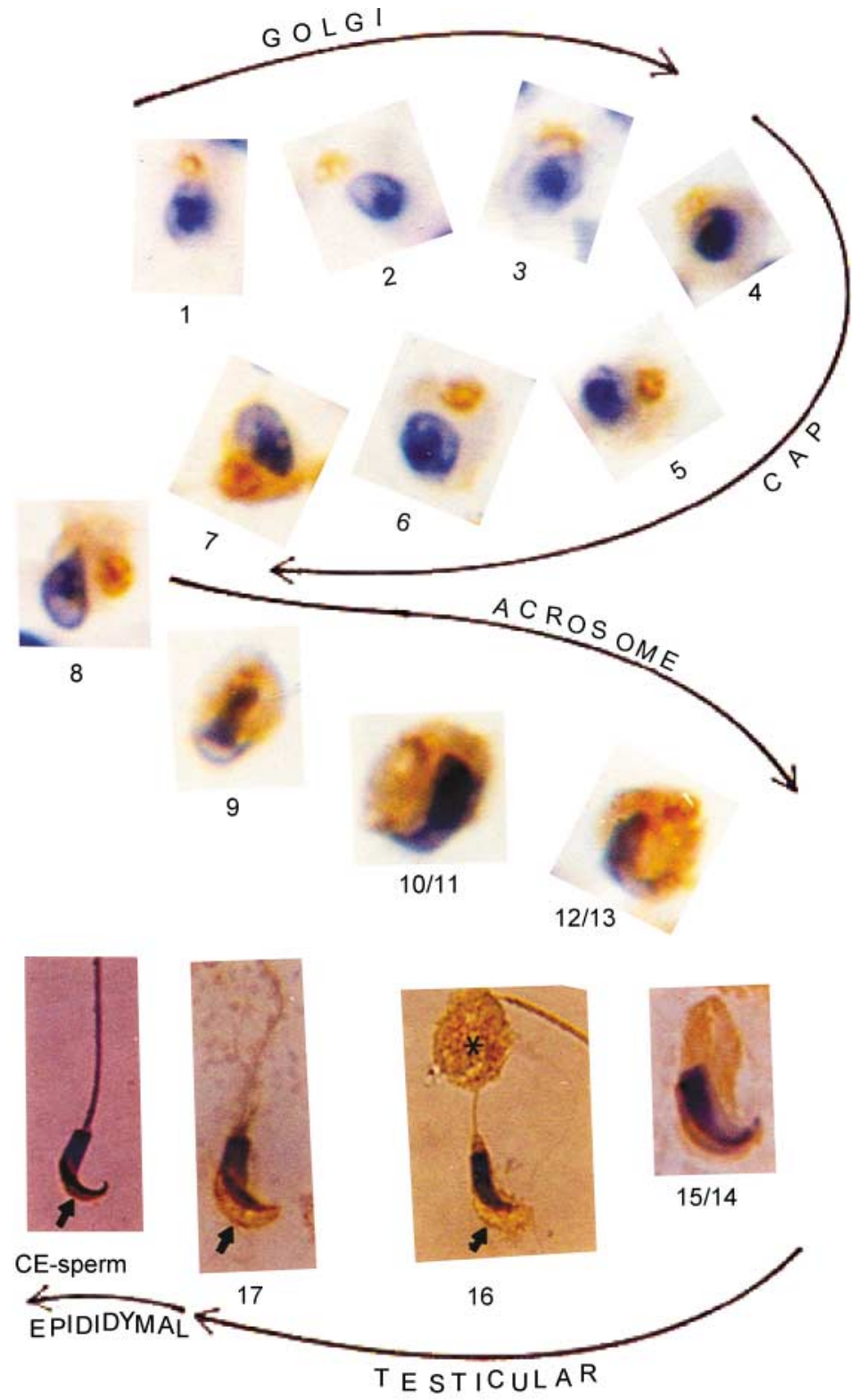

M A T U R A T I O N
Figure 3 Stage-specific localization of immunoreactive RCP in developing male germ cells in hamsters. Immunoreactive RCP was first detected in the form of a granule in step-1 spermatids. The staining was observed in the cytoplasm and developing acrosome, in step-4 spermatids. By step 7, cytoplasmic staining was intense. In step 16, most of the staining was found in the residual body and acrosomal region of the mature sperm. In epididymal sperm (CE-sperm), staining was solely present in germ cells in different stages of spermiogenesis. Spermatids in steps 1-3 constitute the Golgi phase, characterized by the assembly of Golgi components into the acrosome-organizing region. Steps $4-7$ constitute the cap phase characterized by the appearance of a head cap. Steps 8-13 constitute the acrosomal phase characterized by formation of the acrosome. The maturation phase, constituted by steps $14-17$, ends with the formation of a mature testicular spermatozoan. Original magnification: $\times 500$. The description of various steps of hamster spermiogenesis is based on Clermont (1954). step, the pattern of localization of this protein was studied during capacitation and acrosome reaction (Fig. 7). Immunostaining of in vitro-capacitated sperm showed intense staining associated with the acrosomal region (Fig. 7A). Interestingly, however, most of the acrosome-associated immunoreactivity was lost during acrosome reaction (Fig. 7B). Thus acrosome-reacted sperm exhibited a very faint staining associated with the dorsal surface of the acrosome, presumably the inner acrosomal membrane (Fig. 7B). The staining was absent when non-immune IgG was used for detection (Fig. 7C).

In vitro sperm bioassay, carried out to study the role of RCP during capacitation, showed no change in the quality of motility of spermatozoa in the presence of anti-RCP
$\operatorname{lgG}$ (Fig. 8A). However, there was a significant $(P<0.01)$ reduction in the percentage motility $(69.1 \pm 1.1$ versus $51.3 \pm 2.5 \%)$ at $15 \mathrm{~min}$ post-treatment, compared with untreated controls (Fig. 8B). By the sixth hour, the percentage of motility was significantly $(P<0.01)$ lower in antibody-treated samples $(43.8 \pm 3.1 \%)$ compared with controls $(59.7 \pm 2.7 \%$; Fig. $8 \mathrm{~B})$. A decrease in motility upon antibody treatment was evident when the SMI values were compared (Fig. 8C); SMl at $6 \mathrm{~h}$ post-treatment was significantly $(P<0.01)$ lower in anti-RCP-IgG-treated sample compared with untreated sample $(807.2 \pm 103$ versus $1211.3 \pm 59.7$; Fig. 8 C).

The effect of antibody treatment on sperm acrosome reaction was also tested. Anti-RCP IgG treatment of sperm 

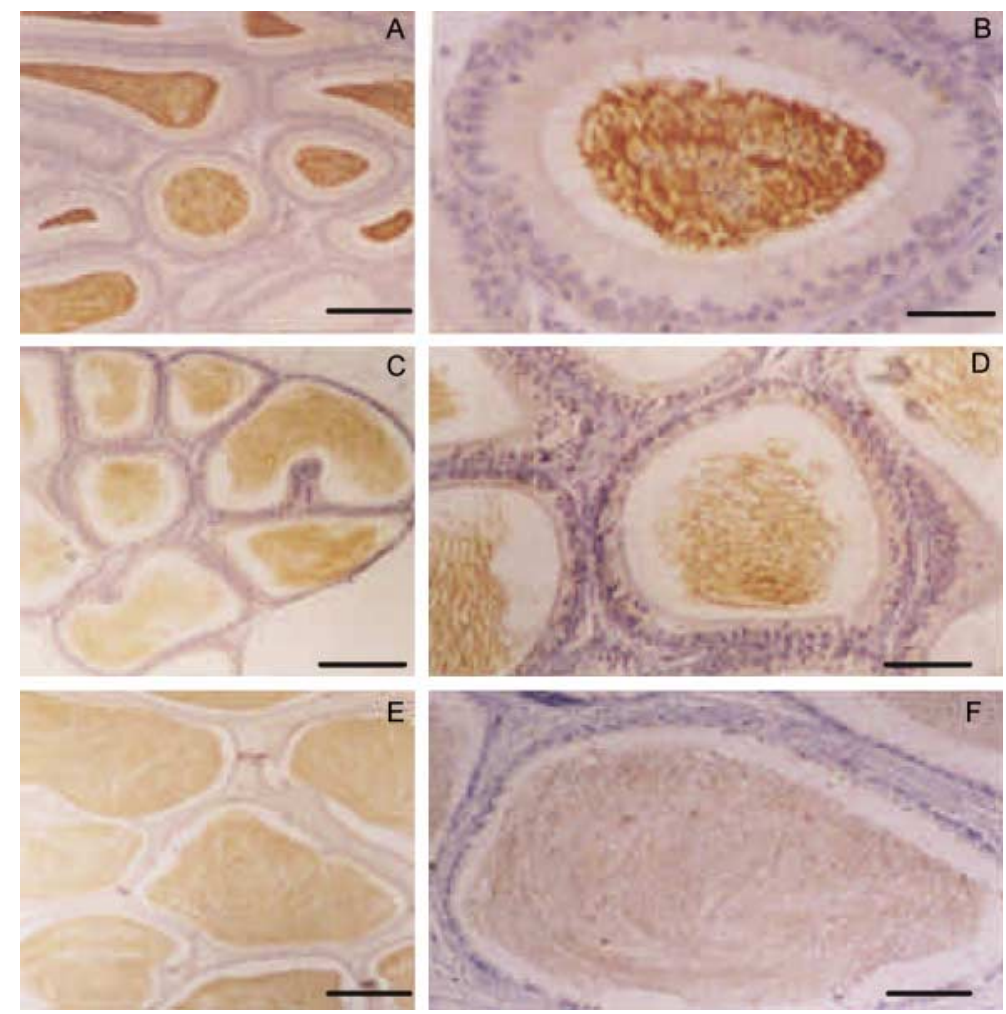

Figure 4 Localization of immunoreactive RCP in epididymis. Immunoreactive RCP was localized to the luminal spermatozoa in the caput (A, B), corpus (C, D) and cauda (E, F) epididymis. No staining was observed in the epithelial cells and the intertubular connective tissues. Original magnifications: A, C, E, $200 \times$; B, D, F, × 500. Scale bars: A, C, E, $69 \mu \mathrm{m} ; \mathrm{B}, \mathrm{D}, \mathrm{F}, 42 \mu \mathrm{m}$.

did not significantly $(P>0.1)$ affect their ability to undergo the acrosome reaction. The percentage of spermatozoa undergoing acrosome reaction in the presence of anti-RCP $\lg$ G was $27.7 \pm 5.9 \%$ compared with those in non-immune-lgG-treated $(29.7 \pm 1.3 \%) \quad$ or -untreated $(29.9 \pm 1.8 \%)$ control samples. Because of the apparent inhibition of sperm motility in the anti-RCP-antibody-treated sperm sample, it was of interest to study the ability of such immunocompromised sperm to penetrate the zonafree oocyte, by carrying out HEPA (Table 1). In this assay, treatment of spermatozoa with anti-RCP IgG resulted in a marked reduction in the number of sperm penetrated per oocyte (by $74 \%$ ), while the number of sperm per penetrated oocyte decreased by $68 \%$. Thus, the number of sperm penetrated per oocyte in the antibody-treated group was significantly $(P<0.001)$ low, i.e. $1.9 \pm 0.4$, when compared with those in the untreated $(7.2 \pm 0.8)$ and non-immune-lgG-treated $(7.3 \pm 1.2)$ groups. Also, the number of sperm per penetrated oocyte in the antibodytreated group was significantly $(P<0.001)$ low $(2.5 \pm 0.3)$ when compared with those in the untreated $(8.1 \pm 0.6)$ and non-immune-lgG-treated $(8.3 \pm 1.0)$ groups (Table 1). However, the percentages of oocytes penetrated were not significantly different among the groups, in either the presence $(74.7 \pm 5.2 \%)$ or absence $(88.3 \pm 4 \%)$ of anti-RCP IgG (Table 1$)$.
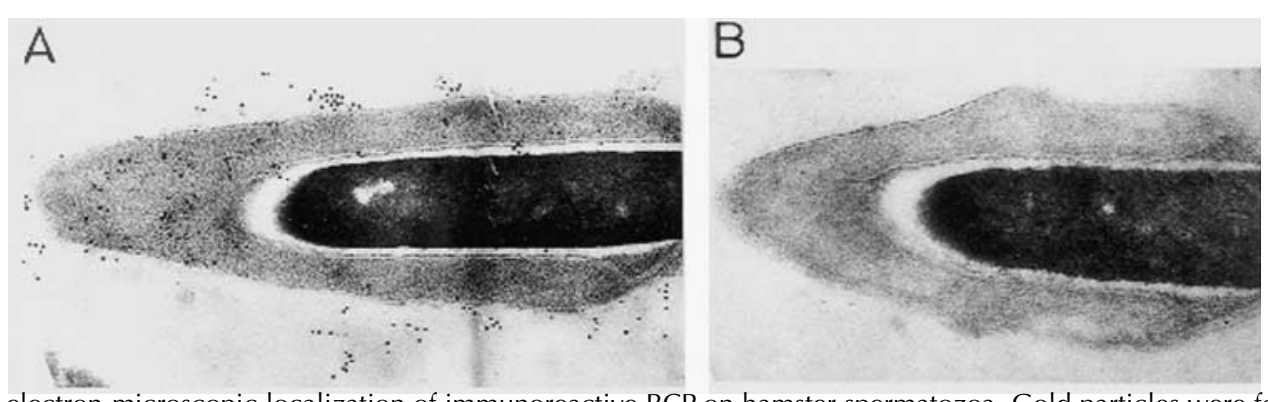

Figure 5 Immunogold electron-microscopic localization of immunoreactive RCP on hamster spermatozoa. Gold particles were found distributed in the matrix and peri-acrosomal membranes of the acrosomal region, in sections treated with anti-RCP antibody (A). A few gold particles were also found associated with the equatorial region of the inner acrosomal membrane (A). No gold particles were found in non-immune-lgG-treated sections (B). Original magnifications: $\times 20000$. 


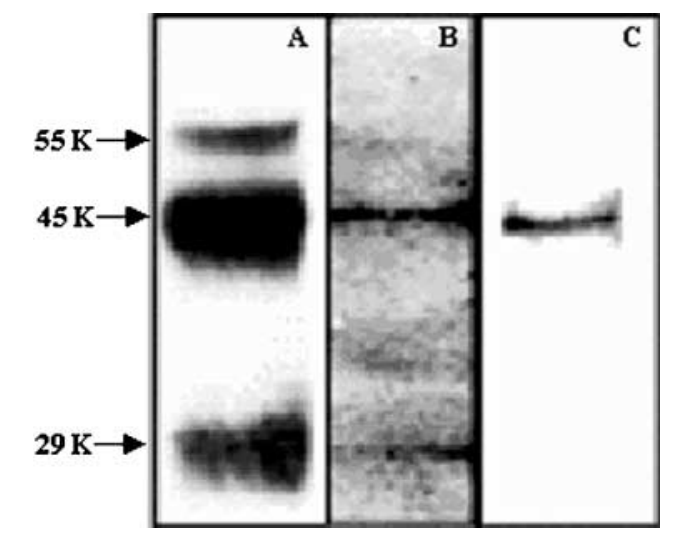

Figure 6 Biochemical analysis of immunoreactive RCP in round spermatid and spermatozoa. (A) Immunoblot analysis of urea-extracted proteins from round spermatids in one dimension showed three bands in the 55, 45 and $29 \mathrm{kDa}$ regions (arrows). (B) Immunoprecipitation of $\left[{ }^{35} \mathrm{~S}\right]$ methionine-labeled proteins of round spermatids using anti-RCP antibodies showed an intense band at $\sim 45 \mathrm{kDa}$. (C) Immunoblot analysis of urea-extracted sperm proteins on one dimension gave an intense band at $45 \mathrm{kDa}$.

\section{Discussion}

In this study we demonstrate the existence of a germ cellspecific, strongly immunoreactive RCP of $45-55 \mathrm{kDa}$ in the acrosomal region of hamster spermatozoa. The protein appears first in differentiating spermatids during spermiogenesis and in mature spermatozoa it is specifically localized in the acrosomal region. While the sperm RCP does not have any crucial role during capacitation or acrosome reaction, it appears to be involved in sperm-egg interaction.

One of the important findings is the conspicuous presence of immunoreactive RCP only in the post-meiotic germ cells, i.e. exclusively in round spermatids and spermatozoa. This is corroborated by a complete absence of immunoreactivity in immature testis (lacking spermatids or spermatozoa) and adult pre-meiotic germ cells, Sertoli cells and Leydig cells. Also, our results of $\left[{ }^{35} \mathrm{~S}\right]$ methionine radiolabeling of round spermatids followed by immunoprecipitation using antibodies to RCP clearly demonstrate the ability of post-meiotic germ cells to biosynthesize de novo the immunoreactive protein. Although RCP-translational activity in round spermatids is evident, the transcriptional regulation of its gene expression during earlier phases of spermatogenesis cannot be ruled out. Importantly, our data show that the immunoreactive RCP is not detectable in spermatocytes, though low amounts of the protein were detectable in spermatids of steps $1-4$, with significant amounts being detected in the later steps of spermatid development, as well as in epididymal spermatozoa. The presence of strong immunoreactivity in the Golgi/acrosomal region, coinciding with the onset of acrosomal biogenesis, is consistent with the earlier report on

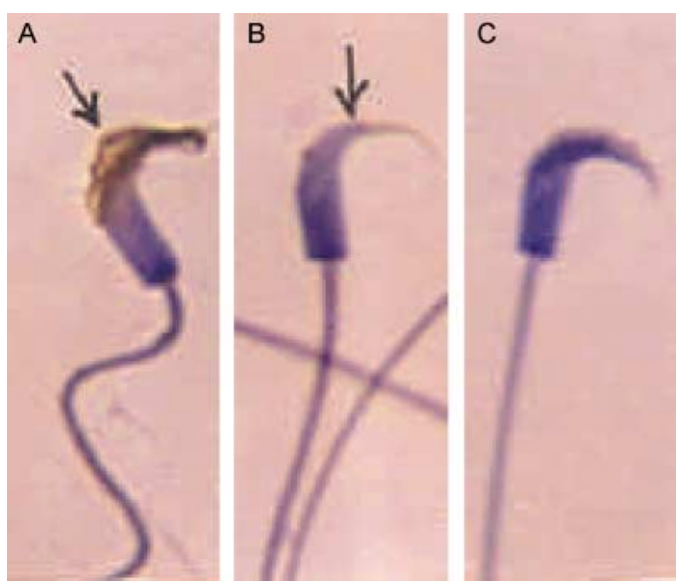

Figure 7 Changing pattern of localization of immunoreactive RCP during capacitation and acrosome reaction. In capacitated sperm, staining was found associated with the acrosomal region of the sperm (A; arrow). However, during the acrosome reaction most of the immunoreactivity was lost (B). A completely acrosome-reacted sperm showed faint staining on the dorsal surface (B; arrow). No staining was found in the non-immune-lgG-treated, acrosome-reacted sperm (C).

the association of this protein with the head region of a few mammalian spermatozoa (Bhat et al. 1995). Such a pattern of immunolocalization that we observed is shared by several other acrosomal-specific proteins, such as Tep22 (Neesen et al. 2002), proacrosin (Phi-Van et al. 1983), protein disulfide isomerase (Ohtani et al. 1993), SP-10 (Kurth et al. 1993), SIAA (Jimenez et al. 1994), rat 2B1 (Jones et al. 1996), ACIII (Gautier-Courteille et al. 1998), Kir3.2d (Inanobe et al. 1999), Acrin1 (MN7) (OhOka et al. 2001) and CYP51 (Cotman et al. 2001). However, the site of biosynthesis of immunoreactive RCP in various mammalian species (Subramanian \& Adiga 1996) remains to be investigated.

The cytoplasmic appearance of immunoreactive RCP in elongating spermatids and residual body may be functionally important from the point of view of sperm maturation in the hamster. One of the highlights of the present study is the exclusion of the bulk of the antigen, associated with Golgi remnants/granules, into the residual body during the terminal phase of spermiogenesis. This gains significance with the finding that most of the $29 \mathrm{kDa}$ fragment observed on the immunoblot of round-spermatid proteins was lost in mature epididymal sperm. This could be indicative of partial or complete release of these immunoreactive components into the residual body of the developing spermatid at the end of testicular sperm development. It could, therefore, be possible to envision a role for these immunoreactive RCP fragments during spermiogenesis. Further studies would be required to assess their role, if any, during hamster sperm development.

The pattern of immunostaining in the acrosomal region of spermatozoa did not change during either epididymal transit or capacitation, indicating a role for the antigen in 


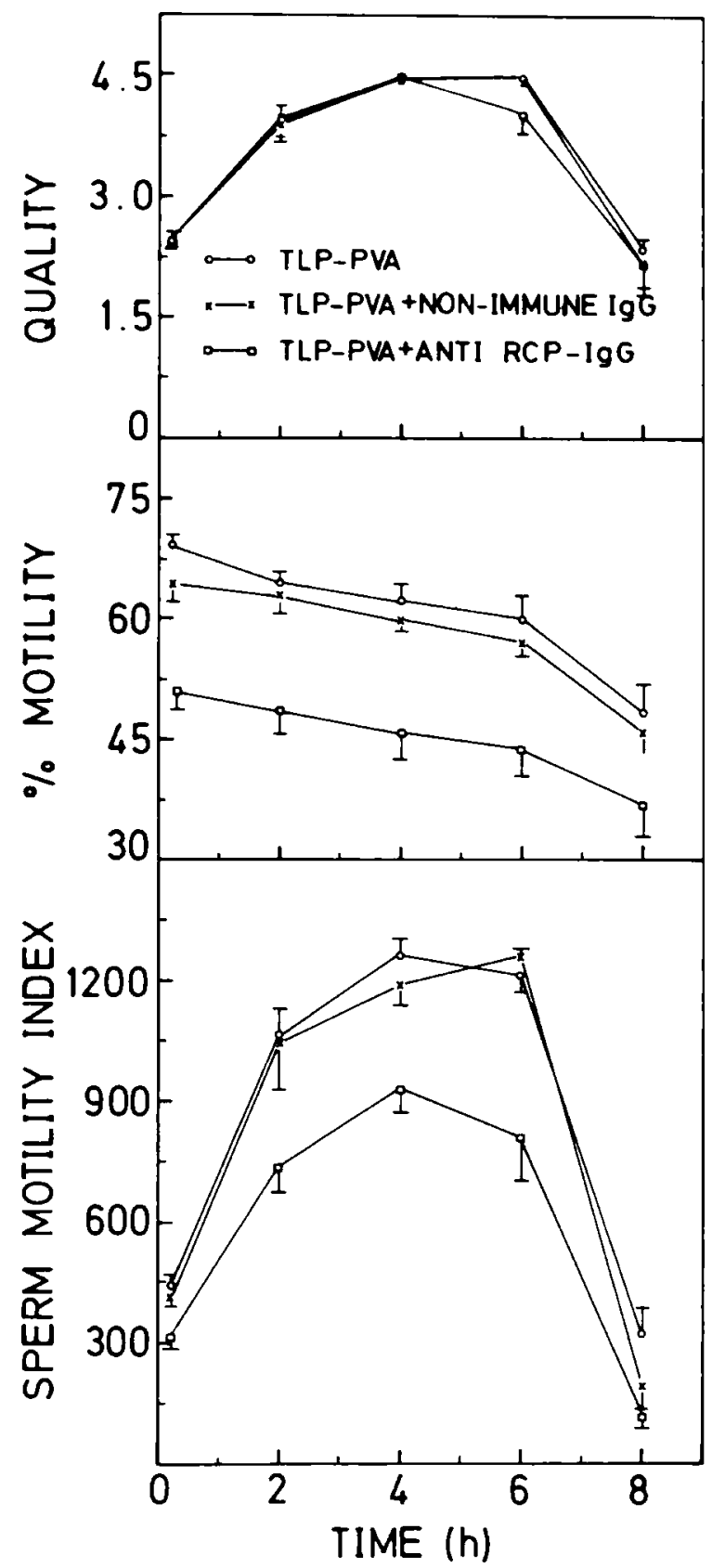

Figure 8 Effect of RCP antibodies on capacitation of hamster spermatozoa in an in vitro sperm bioassay. Addition of anti-RCP IgG $(10 \mu \mathrm{g} / \mathrm{ml})$ to sperm in culture did not have any effect on the quality of motility (A) while significantly reducing the percentage of motile spermatozoa (B). This was reflected in the SMI value (C) that was significantly lower in anti-RCP-treated spermatozoa compared with controls. Significance levels, $P<0.01$. TLP-PVA, Tyrode's medium containing lactate, pyruvate and polyvinyl alcohol.

post-capacitation events. Of interest here is the observation that most of the immunostaining is lost, following acrosome reaction, leaving only a marginal staining detectable in acrosome-reacted spermatozoa. This may be due to an incomplete loss of the acrosome and/or to the presence of a small amount of the antigen in the inner acrosomal membrane. This possibility is indeed consistent with our obser- vation of the appearance of immunogold particles being associated with the inner acrosomal membrane and the matrix components. Loss of the immunoreactive RCP following acrosome reaction, coupled with its presence in the acrosomal matrix, may indicate a possible role for this antigen in regulating acrosomal function involving release of various hydrolytic enzymes required for sperm penetration into the oocyte (Dicarlantonio \& Talbot 1988, Olson et al. 2003). Such a role has been assigned to the $22 \mathrm{kDa}$ glycoprotein in the hamster (Longo et al. 1990).

In view of the above and also because we did not observe any discernible effect of the anti-RCP antibodies either on capacitation or acrosome reaction, we investigated the immunological interference of the protein on sperm-egg interaction, in order to understand its possible role in the downstream events of sperm function. Incubation of spermatozoa with antibodies to RCP resulted in a significant reduction in the number of spermatozoa per penetrated oocyte compared with the untreated or nonimmune-IgG-treated control spermatozoa. This may be due to the effect of the antibody on the parameters governing sperm motility. Indirect evidence stems from our findings on the reduced percentage of motile spermatozoa following anti-RCP-IgG treatment and the sperm's interaction with oolemma being affected by the antibodies. However, it should be noted that a sperm's ability to interact with a zona-free oocyte is not the same as zona-intact oocyte. Pertinent to this is a report of anti-SP-10 antibody inhibiting hamster sperm binding to hamster oolemma but not to human zona pellucida (Hamatai et al. 2000). Despite these, we preferred HEPA in the current study to in vitro fertilization, since the former allows quantitative assessment on the sperm's fertilizing potential. It is known that antibodies to sperm antigens could affect sperm-oocyte interaction in many ways. For example, antibodies to MH61 inhibit sperm penetration into zona-free oocytes without affecting the numbers of sperm binding to the same oocyte (Kawamoto et al. 1999). Although, the mechanism of this inhibitory effect on sperm-egg interaction needs to be fully understood, based on our data it could be suggested that immunoreactive sperm-associated RCP could have an important role during sperm penetration into the oocyte.

It was quite interesting to note that there was an antibody-induced decrease in the percentage of motile spermatozoa in the in vitro sperm bioassay. This could be due to inactivation of a population of spermatozoa by antiRCP antibodies by mechanism that is not clear at this time. One possibility could be the binding of antibodies to the Fc receptor on the sperm tail, disrupting their motility (Zouari et al. 1992). Antibody-induced agglutination has been reported for SMA-4 (Vernon et al. 1982) and SAGA-1 (Norton et al. 2001). Because we did not observe any sperm clumping in culture, we believe that antibodyinduced agglutination is not the factor leading to a decrease in the percentage of motile spermatozoa.

Our data on the biochemical characteristics of the immunoreactive RCP in developing spermatids indicate 
that the protein could be polymorphic with molecular masses ranging from 29 to $55 \mathrm{kDa}$, with the existence of these components being defined by the stage(s) of developing spermatids. Our preliminary studies attribute the observed variation in the molecular sizes of sperm RCP as being due to differentially denatured forms of the same protein (A Sreekumar \& P B Seshagiri, unpublished observations). In this context, several sperm antigens with a role in fertilization have been reported to exhibit polymorphism in their molecular size (Diekman \& Herr 1997, Naz 2000). This polymorphism has been attributed to proteolytic cleavage, as in sp42 (Berruti \& Borgonovo 1996), differential glycosylation, as in SP-10 (Herr et al. 1990), or subunit structure, as in fertilin- $\beta$ (Blobel et al. 1992).

Interestingly, the pattern of immunoreactivity observed for male germ cell-specific RCP using both immunocytochemical and immunoblot analysis was similar using antibodies against either native or denatured preparations of chicken RCP or against various peptide stretches of the protein. This is strongly indicative of the conservation of epitopes in the mammalian protein compared with its avian counterpart. No report, however, is available on the electrophoretic migratory profile and other biochemical characteristics of the immunoreactive mammalian sperm RCP except in the hamster, as described in the present study.

In summary, the present study reveals the existence in hamster spermatids and spermatozoa of an antigenic protein that has a molecular mass ranging from 29 to $55 \mathrm{kDa}$ and is strongly immunoreactive to chicken RCP. The protein forms an integral part of the acrosome and does not appear to have any role during capacitation and acrosome reaction. It has, however, an important role in sperm-egg interaction. Its specific appearance at the Golgi/acrosome region of the developing spermatid makes sperm RCP a candidate marker to study the various steps of mammalian spermatogenesis. It could also provide an ideal tool for evaluating developmental defects in the acrosome during germ cell development, such as round cell syndrome (Jassim \& Festenstein 1987).

\section{Acknowledgements}

Financial support from the Indian Council of Medical Research and Council of Scientific and Industrial Research, New Delhi is gratefully acknowledged. The authors thank Professor P R Adiga and Dr S Sarada for their advice and for providing antibodies used in the study, Professor R R Dighe for help in centrifugal elutriation analysis, $\mathrm{Mr} J \mathrm{R}$ Sunil for technical support and Ms M S Padmavathi for help in the preparation of the manuscript. The authors declare that there is no conflict of interest that would prejudice the impartiality of this scientific work.

\section{References}

Adiga PR, Subramanian S, Rao J \& Kumar M 1997 Prospects of riboflavin carrier protein (RCP) as an antifertility vaccine in male and female mammals. Human Reproduction Update 3 325-334.
Ain R, Uma Devi K, Shivaji S \& Seshagiri PB 1999 Pentoxifyllinestimulated capacitation and acrosome reaction in hamster spermatozoa: involvement of intracellular signalling molecules. Molecular Human Reproduction 5 618-626.

Aravindan GR, Ravindranath N, Gopalakrishnan K \& Moudgal NR 1990 DNA flow-cytometric analysis of testicular germ cell populations of the bonnet monkey (Macaca radiata) as a function of sexual maturity. Journal of Reproduction and Fertility 89 397-406.

Bavister BD 1989 A consistently successful procedure for in vitro fertilization of golden hamster eggs. Gamete Research 23 139-158.

Bavister BD \& Andrews JC 1988 A rapid sperm motility bioassay procedure for quality-control testing of water and culture media. Journal of In Vitro Fertilization and Embryo Transfer 5 67-75.

Bavister BD, Rogers BJ \& Yanagimachi R 1978 The effects of cauda epididymal plasma on the motility and acrosome reaction of hamster and guinea pig spermatozoa in vitro. Biology of Reproduction 19 358-368.

Berruti G \& Borgonovo B 1996 sp42, the boar sperm tyrosine kinase, is a male germ cell-specific product with a highly conserved tissue expression extending to other mammalian species. Journal of Cell Science 109 851-858.

Bhat KG, Malhotra P, Karande AA \& Adiga PR 1995 Immunohistochemical localization of riboflavin carrier protein in testicular cells of mammals. Indian Journal of Experimental Biology 33 12-16.

Blobel CP, Wolfsberg TG, Turck CW, Myles DG, Primakoff P \& White JM 1992 A potential fusion peptide and an integrin ligand domain in a protein active in sperm-egg fusion. Nature $\mathbf{3 5 6}$ $248-252$.

Bucci LR, Brock WA, Johnson TS \& Meistrich ML 1986 Isolation and biochemical studies of enriched populations of spermatogonia and early primary spermatocytes from rat testes. Biology of Reproduction 34 195-206.

Clermont Y 1954 Cycle de l'epithelium seminal et mode de renouvellement des spermatogonies chez le hamster. Reviews of Cancer Biology 13 208-245.

Cotman M, Rozma D, Banek L \& Jezek D 2001 Localisation of lanosterol 14-alpha-demethylase in round and elongated spermatids of the mouse testis: an immunoelectron microscopic and stereological study. Pflugers Archives 442 R167-R168.

Davis JT \& Ong DE 1992 Synthesis and secretion of retinol-binding protein by cultured rat Sertoli cells. Biology of Reproduction $\mathbf{4 7}$ 528-533.

Dean RC \& Moul JW 1998 New tumor markers of testis cancer. Urologic Clinics of North America 25 365-373.

DiCarlantonio G \& Talbot P 1988 Evidence for sequential deployment of secretory enzymes during the normal acrosome reaction of guinea pig sperm in vitro. Gamete Research 21 425-438.

Diekman AB \& Herr JC 1997 Sperm antigens and their use in the development of an immunocontraceptive. American Journal of Reproductive Immunology 37 111-117.

Gautier-Courteille C, Salanova M \& Conti M 1998 The olfactory adenylyl cyclase III is expressed in rat germ cells during spermiogenesis. Endocrinology 139 2588-2599.

Hamatani T, Tanabe K, Kamei K, Sakai N, Yamamoto Y \& Yoshimura YA 2000 Monoclonal antibody to human SP-10 inhibits in vitro the binding of human sperm to hamster oolemma but not to human zona pellucida. Biology of Reproduction 62 1201-1208.

Herr JC, Flickinger CJ, Homyk M, Klotz K \& John E 1990 Biochemical and morphological characterization of the intra-acrosomal antigen SP-10 from human sperm. Biology of Reproduction $\mathbf{4 2}$ $181-193$

Inanobe A, Horio $\mathrm{Y}$, Fujita A, Tanemoto $\mathrm{M}$, Hibino $\mathbf{H}$, Inageda $\mathrm{K}$ \& Kurachi Y 1999 Molecular cloning and characterization of a novel splicing variant of the Kir3.2 subunit predominantly expressed in mouse testis. Journal of Physiology 521 19-30.

Jager D, Jager E \& Knuth A 2001 Immune responses to tumor antigens: implications for antigen specific immunotherapy of cancer. Journal of Clinical Pathology 54 669-674. 
Jassim A \& Festenstein H 1987 Immunological and morphological characterisation of nucleated cells other than sperm in semen of oligospermic donors. Journal of Reproductive Immunology $\mathbf{1 1}$ 77-89.

Jimenez C, Sion B, Grizard G, Artonne C, Kemeny JL \& Boucher D 1994 Characterization of a monoclonal antibody to a human intraacrosomal antigen that inhibits fertilization. Biology of Reproduction $\mathbf{5 1} 1117-1125$.

Jones R, Ma A, Hou ST, Shalgi R \& Hall L 1996 Testicular biosynthesis and epididymal endoproteolytic processing of rat sperm surface antigen 2B1. Journal of Cell Science 109 2561-2570.

Kawamoto A, Ohashi K, Kishikawa H, Zhu LQ, Azuma C \& Murata Y 1999 Two-color fluorescence staining of lectin and anti-CD46 antibody to assess acrosomal status. Fertility and Sterility $\mathbf{7 1}$ 97-501.

Kurth BE, Wright RM, Flickinger CJ \& Herr JC 1993 Stage-specific detection of mRNA for the sperm antigen SP-10 in human testes. Anatomical Record 236 619-625.

Laemmli UK 1970 Cleavage of structural proteins during the assembly of the head of bacteriophage T4. Nature 227 680-685.

Longo FJ, Cook S \& Baillie R 1990 Characterization of an acrosomal matrix protein in hamster and bovine spermatids and spermatozoa. Biology of Reproduction 42 553-562.

Monaco HL 1997 Crystal structure of chicken riboflavin-binding protein. EMBO Journal 16 1475-1483.

Naz RK 2000 Fertilization-related sperm antigens and their immunocontraceptive potentials. American Journal of Reproductive Immunology 44 41-46.

Neesen J, Hartwich T, Brandhorst G, Aumuller G, Glaser B, Burfeind P \& Mendoza- Lujambio I 2002 Tep22, a novel testicular expressed gene, is involved in the biogenesis of the acrosome and the midpiece of the sperm tail. Biochemical and Biophysical Research Communications 297 737-748.

Norton EJ, Diekman AB, Westbrook VA, Flickinger CJ \& Herr JC 2001 RASA, a recombinant single-chain variable fragment (scFv) antibody directed against the human sperm surface: implications for novel contraceptives. Human Reproduction 16 1854-1860.

O'Brien DA 1987 Stage-specific protein synthesis by isolated spermatogenic cells throughout meiosis and early spermiogenesis in the mouse. Biology of Reproduction 37 147-157.
Oh-Oka T, Tanii I, Wakayama T, Yoshinaga K, Watanabe K \& Toshimori K 2001 Partial characterization of an intra-acrosomal protein, human acrin1 (MN7). Journal of Andrology 22 17-24.

Ohtani H, Wakui H, Ishino T, Komatsuda A \& Miura AB 1993 An isoform of protein disulfide isomerase is expressed in the developing acrosome of spermatids during rat spermiogenesis and is transported into the nucleus of mature spermatids and epididymal spermatozoa. Histochemistry 100 423-429.

Olson GE, Winfrey VP \& Nagdas SK 2003 Structural modification of the hamster sperm acrosome during post testicular development in the epididymis. Microscopic Research Techniques 61 46-55.

Phi-Van L, Muller-Esterl W, Florke S, Schmid M \& Engel W 1983 Proacrosin and the differentiation of the spermatozoa. Biology of Reproduction 29 479-486.

Subramanian S \& Adiga PR 1996 Hormonal modulation of riboflavin carrier protein secretion by immature rat Sertoli cells in culture. Molecular and Cellular Endocrinology 120 41-50.

Subramanian S, Karande AA \& Adiga PR 2000 Immunocontraceptive potential of major antigenic determinants of chicken riboflavin carrier protein in the female rat. Vaccine 19 1172-1179.

Towbin H, Staehelin T \& Gordon J 1979 Electrophoretic transfer of proteins from polyacrylamide gels to nitrocellulose sheets: procedure and some applications. PNAS 76 4350-4354.

Vernon RB, Muller CH, Herr JC, Feuchter FA \& Eddy EM 1982 Epididymal secretion of a mouse sperm surface component recognized by a monoclonal antibody. Biology of Reproduction 26 523-535.

White HB 3rd \& Merrill AH Jr 1988 Riboflavin-binding proteins. Annual Review of Nutrition 8 279-299.

Yanagimachi R 1994 Fertility of mammalian spermatozoa: its development and relativity. Zygote 2 371-372.

Zouari R, De Almeida M \& Feneux D 1992 Effect of sperm-associated antibodies on the dynamics of sperm movement and on the acrosome reaction of human spermatozoa. Journal of Reproductive Immunology 22 59-72.

Received 10 October 2004

First decision 26 November 2004

Revised manuscript received 10 December 2004

Accepted 21 December 2004 